\title{
A Tragédia de Mariana (MG): Aforizações, Mídias e Argumentação ${ }^{1}$
}

\author{
The Tragedy in Mariana (MG): \\ Aphorizations, Media and Argumentation
}

\section{Glaucia Muniz Proença Lara}

Universidade Federal de Minas Gerais - UFMG - Brasil

\begin{abstract}
Resumo: Em situações de catástrofes ou tragédias de grandes proporções, como foi o caso do rompimento da barragem de rejeitos da mineradora Samarco, em Mariana MG, as vozes das vítimas - pessoas agora despossuídas de tudo ou de praticamente tudo - ganham destaque, dividindo o espaço midiático com a fala das autoridades e dos especialistas. Articulando essa questão com a noção de aforização, proposta por Maingueneau (2012), nosso objetivo é analisar o caderno especial do jornal Estado de Minas (05/12/2015), intitulado: "Vozes de Mariana: a dor em primeira pessoa" para verificar como se constroem as aforizações secundárias (ou seja, aquelas que são destacadas de um texto sob a forma de citações, títulos, intertítulos e/ou legendas de foto), que têm como locutores/aforizadores as vítimas da referida tragédia. Para tanto, articularemos a Análise do Discurso francesa com contribuições da Semântica Argumentativa (ver, por exemplo, DUCROT, 1987; KOCH, 1992), de modo a apreender, nas aforizações examinadas, "marcas" linguísticas, como a seleção vocabular, os modalizadores, os marcadores de pressuposição, entre outras, que nos permitam reconstruir os sentimentos (a "dor") manifestados por essas "vozes anônimas" diante da tragédia. Assumimos, assim, a influência fundamental que as mídias exercem na construção da opinião pública, na medida em que, ao destacar ou silenciar determinadas vozes, elas vão (con)formando imagens dos eventos noticiados e dos atores que deles participam.
\end{abstract}

Palavras-chave: Discurso. Aforizações. Marcas argumentativas. Tragédia. Mídias.

Abstract: In situations of disaster or tragedy of major proportions, as it was the case of the disruption of the dam belonging to the mining company Samarco, in Mariana - MG, the voices of the victims - people now dispossessed of all or almost all - are highlighted, dividing media space with the speech of authorities and experts. Articulating this issue with the notion of aphorization proposed by Maingueneau (2012), our goal is to analyze the special section of the newspaper Estado de Minas (12/05/2015 ), entitled: "Mariana voices: pain in the first person" ("Vozes de Mariana: a dor em primeira pessoa"), so as to find out how secondary aphrorizations (i.e. those that are detached from a text in the form of titles, intertitles and/or photo captions) related to the victims are (re)constructed by the newspaper. Articulating French Discourse Analysis with the contributions of Argumentative Semantics (see, for example, DUCROT $1987, \mathrm{KOCH}, 1992)$, we intend to grasp, in the examined aphorizations, linguistic "marks", such as vocabulary selection, modalizers, presupposition markers, among others, that allow us to reconstruct the feelings ("the pain") manifested by these "anonymous voices" about the tragedy. We assume, therefore, the fundamental role that the media play in the construction of public opinion, to the extent that, by highlighting or silencing certain voices, they will (con)form images of the events and of the participating actors.

Keywords: Discourse. Aphorizations. Argumentative marks. Tragedy. Media.

\footnotetext{
${ }^{1}$ Trabalho apresentado no IV Simpósio Internacional sobre Análise do Discurso: Discurso e Desigualdade Social, realizado pelo Núcleo de Análise do Discurso da Faculdade de Letras/UFMG, em 2016. Uma primeira versão deste texto encontra-se nos anais do referido evento.
} 


\section{Introdução}

No dia 05 de novembro de 2015, uma barragem de rejeitos da mineradora Samarco se rompeu próximo à cidade de Mariana (MG). Uma enxurrada de 62 milhões de metros cúbicos de lama aniquilou o distrito de Bento Rodrigues, causando 19 mortes. A onda de lama devastou outros sete distritos de Mariana e contaminou os rios Gualaxo do Norte, do Carmo e Doce, atingindo, inclusive, o litoral capixaba, numa área equivalente a mais de seis vezes o tamanho da cidade de São Paulo. Os prejuízos foram calculados em mais de $R \$ 100$ milhões, segundo o prefeito de Mariana, Duarte Júnior. Eis, em poucas linhas, a síntese da tragédia que se abateu sobre o município mineiro de Mariana e seus distritos, conforme consta no site da Veja online.

Um mês depois, em 05/12/2015, o jornal Estado de Minas lançou um Caderno Especial, intitulado "Vozes de Mariana: a dor em primeira pessoa", trazendo depoimentos das vítimas desse terrível desastre ambiental. Como se anuncia na primeira página do caderno, trata-se de "gente que perdeu gente, gente que perdeu bens materiais, gente que perdeu as referências do passado, gente que ganhou traumas e cicatrizes". Nesse caso, não são autoridades ou porta-vozes que falam sobre as vítimas ou pelas vítimas, como, em geral, acontece nas mídias ${ }^{2}$. Na contramão dessa tendência mais comum, essas vozes oficiais, autorizadas, são deixadas de lado em benefício dos "brasileiros anônimos, vítimas do descaso criminoso [...] que não podem ser vítimas também do silêncio".

Nesse contexto, à luz da Análise do Discurso francesa (ADF), mais especificamente, das contribuições de D. Maingueneau (2012), é nosso objetivo verificar como se constroem, nos depoimentos selecionados pelo Estado de Minas, as aforizações secundárias, tomadas, grosso modo,

\footnotetext{
2 Por exemplo, em reportagens publicadas nas revistas IstoÉ, Veja e Carta Capital sobre a ocupação do Morro do Alemão RJ pelo Exército e pela Polícia Militar, a "voz" privilegiada era, via de regra, a dos dirigentes (Governador, Prefeito, Secretário de Segurança do Estado etc), sendo a voz dos moradores da referida favela sistematicamente "apagada" (para maiores informações, ver CAMPOS; LARA, 2013).
}

como enunciados destacados de textos que são "alçados" à condição de citações, títulos, intertítulos e/ou legendas de foto. Para tanto, articularemos a ADF com contribuições da Semântica Argumentativa (ANSCOMBRE; DUCROT, 1983; DUCROT, 1987; $\mathrm{KOCH}, 1984$, 1992), de modo a apreender, nas aforizações examinadas, "marcas" linguísticas, como a seleção vocabular, os modalizadores, os marcadores de pressuposição, entre outras, que nos permitam reconstruir os sentimentos (a "dor") manifestados pelas ditas "vozes anônimas" diante da tragédia.

\section{Aforização e mídias: uma relação complexa}

A noção de aforização, conforme foi definida brevemente na Introdução, situa-se no domínio da ADF - ou do que o próprio Maingueneau (2004, p. 202) prefere chamar de "tendências francesas da análise do discurso". Para explicar a criação desse termo, pouco satisfatório no seu entender, diz Maingueneau (2012, p. 22) que aphorizo, em grego antigo, seria uma operação de determinação e aphorisma, uma definição. O autor, no entanto, admite ter-se inspirado no uso contemporâneo, que toma o aforisma como uma frase sentenciosa que resume, de alguma maneira, uma verdade fundamental, com a ressalva de que a aforização, tal como ele a entende, vai além dos enunciados sentenciosos, aplicando-se ao "conjunto de frases sem texto". Essa afirmação, que é retomada no título do livro do autor, que trata da aforização - Les phrases sans text (2012) ou Frases sem texto (na tradução brasileira de 2014) - pode soar estranha. Afinal, o que seria uma "frase sem texto"?

Para responder a essa pergunta, recorremos ao próprio Maingueneau (2012) para quem essa condição da aforização (de ser uma frase sem texto) remete a um tipo de enunciação que obedece a uma outra lógica, distinta da do texto. Do ponto de vista mais imediato, isso significa que a aforização não é nem precedida nem seguida de outras frases com as quais estaria ligada por relações de coesão, de modo a formar uma unidade textual, ancorada num gênero 
de discurso. Logo, o que caracteriza a aforização é a recusa em entrar na lógica do texto e do gênero de discurso, o que não significa, por outro lado, que ela seja destituída de contexto. O que ocorre é que, no caso das aforizações que nos interessam aqui - as secundárias $^{3}$ - o contexto se desdobra em dois: um contexto fonte e um contexto de recepção, sendo a distância entre esses dois contextos responsável, via de regra, pelas alterações a que o contexto de recepção submeteria o enunciado destacado, ativando, inclusive, potencialidades semânticas outras, para além daquelas presentes no contexto original (MAINGUENEAU, 2012, p. 25-27).

Cabe ressaltar ainda que há dois tipos de aforização secundária: por destacamento forte e por destacamento fraco. No primeiro, os enunciados destacados rompem com o texto de origem - ou seja, do ponto de vista do consumidor de mídias, esse texto não existe -, enquanto, no segundo, os enunciados destacados são vizinhos do texto de origem. Portanto, no destacamento fraco, os enunciados mantêm um elo com o texto de origem, embora isso não implique uma fidelidade absoluta. No presente trabalho, abordaremos aforizações tanto por destacamento forte quanto por destacamento fraco, pois o que nos interessa é reunir as aforizações apreendidas a partir dos depoimentos das vítimas da tragédia de Mariana (MG), para verificar, afinal, como elas (re)constroem discursivamente o fenômeno: suas impressões, seus sentimentos, suas opiniões.

Sem a intenção de ser exaustivo, Maingueneau (2012, p. 58) lista alguns índices que orientam para um diagnóstico de aforização: índices textuais (preferência por enunciados constituídos de uma única frase); índices lexicais (presença de verbos como repetir e martelar, que ressaltam o caráter memorizável da aforização); índices aspectuais (caráter genérico do enunciado); índices sintáticos e prosódicos (construções simétricas, em

\footnotetext{
3 As aforizações podem ser primárias (autônomas), como é o caso dos provérbios, máximas e adágios, ou secundárias (aquelas que são destacadas de um texto). O presente trabalho volta-se, de forma privilegiada, para esse segundo tipo de aforização, que, segundo o próprio Maingueneau (2012), não foi ainda suficientemente estudado, ao contrário do primeiro.
}

quiasma...); índices semânticos (presença de tropos: metáforas, paradoxos...), entre outros.

O autor, porém, ressalta a impossibilidade de se determinarem a priori quais são as condições necessárias e suficientes para que uma sequência destacada assuma o papel de aforização e conclui que a aforização pura não existe, já que cada aforização pertence necessariamente a um tipo e sofre coerções por esse pertencimento. Isso nos obriga, então, a raciocinar em termos de aforizações mais ou menos prototípicas (MAINGUENEAU, 2012, p. 49-50).

Considerando que as aforizações que serão examinadas na próxima seção foram recortadas pelas mídias - mais especificamente, por um jornal impresso ${ }^{4}$-, em detrimento de outros enunciados igualmente disponíveis ao destacamento, não podemos deixar de mencionar, mesmo que brevemente, o papel das instâncias midiáticas como produtoras e distribuidoras de esquemas de significação e de interpretação do mundo.

Charaudeau (2006), por exemplo, afirma que, independentemente das críticas que se possam fazer às mídias, elas desempenham um papel fundamental no âmbito da democracia: o de informar a população sobre fatos e acontecimentos que ocorrem no mundo, fazendo circular explicações sobre eles e abrindo espaço para o debate. Por outro lado, considerando que os cidadãos sempre entram em contato com o acontecimento tal como ele é filtrado pelas mídias - já que eles nunca têm acesso ao "acontecimento bruto" - não se pode perder de vista que as mídias escolhem o que tornar visível (e - acrescentamos determinam o modo como esse visível deve ser "tornado visível").

Vemos, assim, que as mídias detêm uma considerável "margem de manobra", ao selecionar a informação a ser veiculada - afinal, escolher anunciar uma notícia é fazê-la existir -, operando recortes nesse material (decidindo o que será ou não excluído, as "vozes" que serão agenciadas ou, ao contrário,

\footnotetext{
${ }^{4}$ Nesta ocorrência e nas demais, ao longo deste artigo, o termo "jornal" está sendo tomado de forma genérica para abarcar um "todo hierárquico" de profissionais da notícia, que vai desde aqueles que propõem pautas até a instância final - a do editor, passando por repórteres, redatores etc.
} 
silenciadas) e dando-Ihe uma organização específica, entre outras possíveis. Nessa perspectiva, as mídias (no nosso caso, um jornal impresso), ao "des(con)textualizarem" certos enunciados, separando-os do seu contexto de origem (o do texto fonte), e os destacarem em outros (novos) contextos, contribuem para a (re)construção discursiva dos fenômenos focalizados: aqui, o rompimento da barragem de Fundão, em Mariana (MG), e suas nefastas consequências. Afinal, se as falas são das vítimas, a escolha do que será destacado (ou não), feita pelo jornal, direciona a interpretação do leitor. Isso nos leva a compartilhar a opinião de Charaudeau (2006a) sobre o papel fundamental que as mídias desempenham na formação da opinião pública ${ }^{5}$.

Em suma: neste artigo, privilegiaremos os enunciados destacados (aforizações) presentes no Caderno Especial do Estado de Minas (05/12/2015), procurando apreender as marcas linguísticas da argumentação que permitam a (re)construção discursiva da tragédia de Mariana (MG) na voz das próprias vítimas, embora, como dissemos, essa (re)construção passe, em grande medida, pelas mãos da maquinaria midiática. Para tanto, como foi dito, buscaremos as contribuições da Semântica Argumentativa de Ducrot, conforme se verá na próxima seção.

\section{A argumentação na/pela linguagem: contribuições de Ducrot}

Denominando a disciplina no interior da qual se situam suas pesquisas como uma "pragmática semântica" ou uma "pragmática linguística", Ducrot (1987, p. 163) admite que, se a ação humana, em geral, pode ser tomada como objeto da pragmática, o termo "pragmática da linguagem" serviria para designar, nesse vasto conjunto de investigações, aquelas que "dizem respeito à ação humana realizada

\footnotetext{
${ }^{5}$ É claro que as mídias não detêm o monopólio da influência social, que é exercida também por outras instâncias, como a escola, a família e a igreja. No entanto, não podemos perder de vista a importância da maquinaria midiática na construção da opinião pública, como mostram os trabalhos de Charaudeau (2006) e Emediato (2013), a que remetemos o leitor interessado em questões relacionadas ao papel das mídias nas democracias contemporâneas.
}

pela linguagem, indicando suas condições e seu alcance". Nesse quadro, o autor se pergunta por que é possível usar certas palavras para influenciar o outro, ou seja, por que "certas palavras, em certas circunstâncias, são dotadas de eficácia".

Um exemplo pode esclarecer melhor as indagações iniciais de Ducrot. Em dois enunciados como: (a) "João vai entrar na política; ele quer ser vereador"; e (b) "João vai entrar na política; ele quer ser ao menos vereador.", a presença de ao menos em (b), leva o destinatário a tirar conclusões diferentes daquelas que tiraria a partir de (a). Assim, de (b) deduz-se que João pretende "alçar voos mais altos" em política: ser prefeito, deputado, governador..., o que se justifica, do ponto de vista argumentativo, pela presença de um elemento linguístico: ao menos. Em outras palavras: esse operador introduz "dado argumento, deixando subentendida a existência de uma escala com outros argumentos mais fortes" (KOCH, 1992, p. 32).

Trata-se, pois, de uma pragmática/semântica de base linguística, também conhecida como "Semântica da Enunciação", em que a noção de argumentação é crucial. Segundo Anscombre e Ducrot (1983, p. 8): "Um locutor realiza uma argumentação quando apresenta um enunciado E1 (ou um conjunto de enunciados) como estando destinado a fazer admitir um outro (ou um conjunto de outros) E2. Nossa tese é a de que há na língua coerções que regem essa apresentação." (grifos do original) ${ }^{6}$.

Dentro desse quadro, é preciso admitir que há enunciados cujo traço constitutivo é o de serem utilizados com a pretensão de orientar o interlocutor para certos tipos de conclusão, com a exclusão de outras, como vimos no exemplo apresentado anteriormente. Cumpre, portanto, determinar sua "orientação argumentativa", isto é, as conclusões para as quais podem servir de argumento. Nessa perspectiva, a argumentatividade não constitui algo apenas acrescentado ao uso linguístico; pelo

\footnotetext{
${ }^{6}$ Tradução livre de: "Un locuteur fait une argumentation lorsqu'il présente un énoncé $E 1$ (ou un ensemble d'énoncés) comme destiné à en faire admettre un autre (ou un ensemble d'autres) E2. Notre thèse est qu'il y a dans la langue des contraintes régissant cette présentation."
} 
contrário, ela está inscrita na própria língua ou, em outras palavras, constitui 0 ato linguístico fundamental. É isso que Koch (1984) chama de "retórica integrada", distinguindo-a da "retórica acrescentada", que remete a dados, fatos, argumentos que se acrescentam à língua (ou, mais especificamente, ao discurso) posteriormente, para sustentar uma dada posição assumida pelo locutor.

Essa argumentatividade inscrita na língua pode manifestar-se por meio de elementos como: os operadores argumentativos, os indicadores modais, os índices de avaliação, os indicadores atitudinais, os marcadores de pressuposição, entre outros. Como já foi dito, são esses elementos que nos permitirão, a partir do estabelecimento de um estreito diálogo entre os estudos da argumentação na língua e a ADF, examinar os enunciados destacados (aforizações) pelo Caderno Especial do Estado de Minas, a partir dos depoimentos das vítimas da tragédia de Mariana (MG).

O que nos leva a optar pela Semântica Argumentativa de Ducrot - e não por outras abordagens da argumentação igualmente possíveis ${ }^{7}$ - são duas razões principais. Primeiramente, porque o que nos interessa mais de perto aqui é examinar como a argumentação se constrói do ponto de vista linguístico ou, nas palavras de Koch (1984), na perspectiva da "retórica integrada". Em segundo lugar, porque temos buscado, já há algum tempo, aproximar a ADF dos estudos pragmáticos (ver, por exemplo, LARA, 2016), com resultados positivos. Aliás, esse diálogo entre as duas disciplinas não é novo: o próprio Maingueneau (1993) se vale das contribuições de Ducrot (1987; ver, sobretudo, o capítulo "Esboço de uma teoria polifônica da enunciação") quando trata da heterogeneidade enunciativa no âmbito da ADF.

Resta, finalmente, explicar por que tomamos as aforizações - e não os depoimentos completos como objeto de análise. Poderíamos dizer que o volume de textos que temos em mãos demandaria

\footnotetext{
7 Lembremos, por exemplo, Amossy e sua argumentação no discurso, em obras como La présentation de soi. Ethos et identité verbale (2010) ou Images de soi dans le discours (1999). Ver também seu artigo « As modalidades argumentativas do discurso », publicado no Brasil (2008).
}

uma pesquisa mais extensa e detalhada para além da produção de um artigo, como o que aqui se propõe. Entretanto, um motivo, a nosso ver, mais relevante se impõe: não podemos perder de vista os muitos "leitores apressados", cujo olhar se limita, com frequência, aos elementos mais "salientes" dos textos midiáticos, como os títulos, as manchetes e as imagens. Nessa perspectiva, cabe ao analista examinar esses "fragmentos" textuais, dada a sua importância na/para a construção de sentidos.

\section{Situando as análises: algumas questões metodológicas}

Do ponto de vista metodológico, como já foi dito, optamos por trabalhar com aforizações secundárias, tanto por destacamento fraco (quando o texto de onde foi recortada a aforização está presente) quanto por destacamento forte (quando não temos acesso ao texto fonte, já que ele está ausente da publicação examinada).

É preciso esclarecer ainda que, embora nossa pesquisa seja descritiva e interpretativa, privilegiando, portanto, o aspecto qualitativo (e não o quantitativo), julgamos importante fornecer ao leitor um panorama geral das aforizações coletadas no Caderno Especial do Estado de Minas (nosso objeto de análise) por meio da apresentação de alguns números.

Assim, encontramos, no referido caderno, 52 aforizações no total, sendo 14 por destacamento forte e 38 por destacamento fraco. Entre essas últimas, 17 são títulos; 14, intertítulos e 4, legendas de foto. Em alguns casos, há apenas uma aforização por depoimento (em geral, sob a forma de título); em outros casos, porém, há duas ou até três aforizações destacadas de um mesmo depoimento (normalmente, título e intertítulo(s) ou título e legenda de foto). Além disso, enquanto as 38 aforizações por destacamento fraco (juntamente com os depoimentos de onde foram retiradas) ocupam 11 das 12 páginas do caderno, inclusive, a 1a página (que funciona como "capa" do caderno), as aforizações por destacamento forte vêm todas elas agrupadas na última página (p. 12), com o título "Outras vozes", a exemplo de seções como 
"Veja essa" e "Semana", publicadas, respectivamente nas revistas Veja e IstoÉ.

Cabem ainda aqui algumas considerações. Em primeiro lugar, todas as aforizações encontradas estão em discurso direto (inclusive, com a presença de aspas), já que reproduzem trechos da fala das vítimas, registrada sob a forma de depoimento (transcrito, possivelmente, a partir de uma entrevista). Isso está em consonância com a posição de Maingueneau (2012) de que as aforizações prototípicas são citações em estilo direto.

No entanto, como o próprio título da matéria anuncia - "a dor em primeira pessoa" -, as aforizações aqui abordadas perdem, via de regra, seu caráter generalizante e, além disso, nem sempre se limitam a enunciados constituídos de uma única frase (outros dois aspectos apontados pelo autor, conforme vimos, como sendo característicos da aforização prototípica). Assim, das 52 aforizações apreendidas apenas uma mantém esse caráter generalizante da aforização prototípica, além de reduzir-se a uma única frase. Trata-se do título (aforização por destacamento fraco): "Uma vida não tem preço" ( $p$. 10).

Diante disso, é preciso deixar claro que estamos trabalhando com aforizações em sentido amplo, ou seja, com aquilo que denominamos em outros trabalhos (ver, por exemplo, LARA, 2013a; 2014) "aforizações periféricas" ou que Assis (2015) chama de "citações" (propriamente ditas) ${ }^{8}$. A justificativa para tal decisão é o ponto de vista adotado pelo próprio Maingueneau (2012, p. 50) - e também já mencionado na seção 1 - de que a aforização pura não existe; de que cada aforização pertence necessariamente a um tipo e sofre coerções por esse pertencimento.

\footnotetext{
8 Buscando compreender se toda aforização pode ser considerada uma citação (e vice-versa), o autor admite que a resposta para esse impasse parece ser, simultaneamente, sim e não. No seu entender, se a retomada é fator preponderante para o fenômeno da aforização (que corresponde à lógica da citação), nem toda citação corresponde a uma aforização. Trechos muito longos, sem características destacáveis, que não marquem posicionamentos generalizantes, entre outros aspectos, podem ter seu caráter aforizante enfraquecido, até mesmo extinto, ainda que utilizem aspas e sejam empregados em discurso direto. Nesse caso, o autor prefere falar em "citação". (cf. ASSIS, 2015, p. 59).
}

Grosso modo, se tomarmos a linha do tempo, podemos agrupar as 52 aforizações em três conjuntos, referentes ao antes, ao durante e ao depois do rompimento da barragem da mineradora Samarco, sendo os dois últimos grupos mais numerosos, como se poderia esperar pelo tipo de matéria produzido. Nossa análise será feita, levando em conta esses três momentos, mas sem estabelecer limites muito rígidos entre um e outro(s), visto que eles se sobrepõem com certa frequência. Não apontaremos, porém, todas as marcas linguísticas da argumentação - o que seria inviável no espaço limitado de um artigo -, mas apenas aquelas que, a nosso ver, mostram-se mais relevantes para a (re)construção discursiva da tragédia e de seus efeitos, por meio das vozes das vítimas, tal como foram destacadas/aforizadas pelo Estado de Minas.

Finalmente, é importante mencionar que, se os enunciados podem sofrer alterações na passagem do texto-fonte à aforização, o que acontece, com certa frequência, levando, inclusive, Maingueneau (2012, p. 20) a admitir que as mídias atuais mostram-se "ostensivamente relaxadas" quando se trata de destacar enunciados de um texto, não nos parece ser o caso aqui. Acontecem alguns cortes entre o texto fonte e a aforização, mas nada que modifique substancialmente o sentido da fala do locutor em seu depoimento (ao contrário do que detectamos em outras publicações já analisadas; ver, por exemplo, LARA, 2013b; 2014). Feitas as considerações e as ressalvas, passemos à análise dos enunciados destacados.

\section{Aforização e marcas linguísticas no discurso da tragédia}

As aforizações que se referem ao antes do acidente (em geral, contraposto ao agora), como era de se esperar, avaliam a vida dos moradores dos distritos atingidos como "feliz" (índice de avaliação) quando comparada à situação pós-tragédia. É o que mostra o enunciado destacado: "A gente reclamava. 
Hoje a gente percebe que era feliz e não sabia." (DFr/intertítulo; depoimento de P. R., p. 7) ${ }^{9}$.

Esse contraste entre o antes e o agora aparece em outros enunciados destacados, sobretudo aqueles que dizem respeito à poluição irreversível do rio Doce. E, embora não haja índices de avaliação explícitos como no caso anterior, podemos pensar em algo como abundante (no antes) vs. escasso (no agora):

a) "Antes da lama, tinha muito bok (peixe), rokrok (garça), rimbom (capivara), pomba (pato)... Tinha bicho que ia beber água. la gundhum (tatu) e ia gran (cobra)." (DFo, depoimento de A., índia krenak de 3 anos de idade, p. 14).

b) "Tenho 50 anos de beira de rio. Vi descer peixe morto do tamanho que nunca pesquei na vida. A mineradora passou e pescou tudo." (DFo; depoimento de A. M. D., p. 14).

c) "Tudo quanto era flor tinha. Tudo foi embora. A água destruiu." (DFr/intertítulo; depoimento de L. M., p. 9).

Nos momentos da tragédia e do pós-tragédia, os índices de avaliação (via de regra, negativos) que podem ser apreendidos nos enunciados destacados remetem, inicialmente, a sentimentos de assombro (estarrecimento), de desespero e de abandono, seguidos, principalmente, de tristeza e desalento pela situação generalizada de devastação, como vemos, por exemplo, em:

d) "As pessoas estavam estarrecidas." (DFr/título; depoimento de L. F., p. 6).

e) "Não achei ninguém. Fiquei sozinha e desesperada." (DFr/legenda de foto; depoimento de P. R., p. 1).

f) "Quando aconteceu a tragédia, eu fiquei doido. Era costume dela [a mãe] tomar banho entre três e meia e quatro horas." (DFr/intertítulo, depoimento de M. J. F., p. 2)

g) "Nossa relação com o rio é bem mais antiga. Sempre estivemos aqui. E agora? Os krenak estão tristes porque o Uatu Nek (Rio Doce) morreu." (DFo, depoimento de I., índio krenak, p. 14).

Do ponto de vista lexical, é importante ainda observar as denominações utilizadas para se referir

\footnotetext{
${ }^{9}$ Esclarecemos que os grifos desta e das demais citações são nossos. Além disso, indicaremos, entre parênteses, se se trata de destacamento forte (DFo) ou de destacamento fraco (DFr) e, nesse último caso, se a aforização aparece como título, intertítulo ou legenda de foto, já que, no caso do DFo, as aforizações aparecem apenas no formato de citações, que vêm agrupadas na última página do caderno, como já foi dito. Por razões éticas, embora os nomes completos das vítimas sejam mencionados no Caderno Especial do Estado de Minas, utilizaremos apenas as iniciais.
}

ao acontecimento de Mariana (MG): tragédia, 11 de setembro (numa analogia à destruição das Torres Gêmeas de Nova York pela organização terrorista alQaeda), pesadelo, coisa ruim, guerra. A título de ilustração, vejamos como se constrói o "movimento argumentativo" referente à associação com a guerra, numa aforização em que ocorre a presença do operador argumentativo de contrajunção mas: "Eu mais oito militares chegamos. Nunca fui a uma guerra, mas era aquilo." (DFr/intertítulo; depoimento de L. F., p. 6).

Segundo Ducrot (1987), o esquema de funcionamento da construção $p$ mas $q$ seria 0 seguinte: de $p$ tire a conclusão possível $R$ (por exemplo, "Não sei o que é uma guerra"); de $q$ tire a conclusão possível não- $R$ (no caso, algo como "O rompimento da barragem me mostrou o que é uma guerra"); de $p$ mas $q$ tire a conclusão possível não- $R$. Portanto, a conclusão possível para o conjunto de enunciados "[...] Nunca fui a uma guerra, mas era aquilo." é não- $R$ (que invalida $R$ ).

Apesar de tudo o que aconteceu, muitos dos entrevistados ainda demostram, no momento póstragédia, esperança e fé em relação ao que está por vir, como mostram as seguintes aforizações:

h) "Só não perdi minha família e a fé em Deus." (DFr/título; depoimento de L. M., p. 9)

i) "A nossa história não pode acabar no dia 05." (DFr/título; depoimento de P. G. A., p. 5)

j) "Não sei o que a gente vai fazer a partir de agora não. Só Jesus... A água vai voltar sim. Deus não esquece dos filhos dele." (DFo; depoimento de M. G., p. 14).

Em h) e j), constatamos a presença de marcadores de pressuposição. Lembremos que, para Ducrot (1987), há duas formas de implícito: o pressuposto e o subentendido. A diferença é que, enquanto o subentendido depende do contexto, da interpretação do outro, o pressuposto é marcado linguisticamente. Assim, em "Só não perdi minha família e a fé em Deus", o marcador "só (não)" instaura o pressuposto de que o locutor perdeu tudo o mais que possuía (moradia, móveis e outros bens materiais, estabilidade, sossego etc). O mesmo raciocínio pode ser aplicado a j), em que o pressuposto é de que não há outra instância (a não 
ser Jesus/Deus) que possa normalizar a situação (a volta da água). Nesse caso, o verbo (vai) voltar também é um marcador de pressuposição, pois apenas pode voltar aquilo que já existia antes, ou seja, a água (limpa) do rio Doce.

Os enunciados destacados que apelam para a instância divina mostram a religiosidade do povo de Mariana (MG) e apontam para um dado curioso: os locutores não atribuem a Deus a causa dos seus infortúnios, preferindo apostar no diabo como desencadeador da tragédia. É o que se vê, por exemplo, em: "O diabo que fez isso" (DFr/título; depoimento de M. do C., p. 11). Fica subentendido aqui que Deus, enquanto fonte de amor e bondade, não poderia ser o causador de um desastre daquelas proporções.

No enunciado i), por seu turno, o modalizador "(não) pode", utilizado de forma enfática, assume praticamente um valor deôntico (eixo da conduta), sugerindo uma espécie de obrigatoriedade no que se refere a ter esperanças na (boa) continuidade da história dos moradores de Mariana (MG). Aqui também encontramos o "não polêmico" de Ducrot (1987, p. 204). É como se o locutor estivesse se posicionando em relação a um enunciador (entendido como uma perspectiva, um ponto de vista, identificado ao senso comum), segundo o qual, a história da cidade e de seus habitantes pudesse acabar ali, a partir da ocorrência da tragédia. Lembremos que, para Ducrot (1987, p. 191-192), se o locutor é o responsável pela enunciação, o enunciador é um ponto de vista, ou uma posição com a qual o locutor se identifica (ou não). Conforme comenta Maingueneau (1993, p. 84), a negação polêmica de Ducrot não implica a rejeição de um locutor, mas de um enunciador mobilizado no discurso, enunciador esse que não é autor de um enunciado efetivamente realizado.

Os marcadores de pressuposição são recorrentes no conjunto das aforizações analisadas e podem indicar também, ao contrário da atitude de esperança e fé manifestadas nas aforizações que acabamos de examinar, uma certa descrença na recuperação do meio ambiente, diante do caos que se instalou ali com o rompimento da barragem de Fundão e o "mar de lama" que invadiu a região. Essa outra atitude pode ser vista, por exemplo, em:

k) "O lugar não dá mais nada." (DFr/título; depoimento de J. P., p. 11)

I) "Isso aqui vai virar uma poeira só." (DFr/título; depoimento de E. S, p. 10)

m) "O pasto virou lama. Os bichos não podem beber a água do rio. Não sei como vou fazer para continuar a criação." (DFo; depoimento de A. R., p. 14).

Os elementos linguísticos assinalados nos enunciados k), l) e m) funcionam como "gatilhos" para desencadear a pressuposição. Podemos, portanto, recuperar a partir deles os conteúdos implícitos (pressupostos) de que o lugar antes era produtivo antes "dava" -; que não é poeira ainda (mas será poeira quando a água da lama secar); que o pasto não era lama antes da tragédia, mas (subentende-se) terra fértil que permitia, inclusive, a criação de animais (continuar a criação implica que ela existia antes). Tudo isso mostra, como foi dito, uma certa descrença na recuperação da região e contrasta com a esperança e a fé (em Deus) de que a situação pode mudar, voltando a ser como era antes.

De qualquer forma, não podemos perder de vista que o "lugar de pessoa", que, "afirma a superioridade daquilo que está ligado às pessoas. Primeiro as pessoas, depois as coisas!..." (ABREU, 2003, p. 90; grifos do original), é reafirmado, nas aforizações selecionadas, como verificamos em:

n) "Uma vida não tem preço." (DFr/título; depoimento de G.S., p. 10)

o) "Encontrei meu filho no ponto de ônibus de Mariana. Não tem sensação mais gostosa. Foi o melhor dia da minha vida." (DFr/intertítulo; depoimento de M. de C., p. 4).

Em n), reencontramos o "não polêmico" de Ducrot (1987, p. 204), que, segundo o autor, remeteria à "propriedade que justificaria a posição do locutor no diálogo cristalizado subjacente à negação polêmica". Em outras palavras, se é possível descrever um bem (no caso, uma vida), dizendo que ela não tem preço, é porque atribui-se-lhe "a (pseudo) propriedade" que legitimaria opor-se a um enunciado que tivesse afirmado que ela (a vida) tem preço. Novamente aqui, temos um locutor que nega não um 
enunciado efetivamente produzido por outrem, mas um ponto de vista, uma perspectiva (ou seja, um enunciador mobilizado no discurso). Relembremos que, para Ducrot (1987, p. 191-192), os enunciadores são seres a quem não se podem atribuir palavras precisas.

Já em o), o índice de avaliação "gostosa" atribuído à a sensação de alguém que reencontra o filho no meio do caos, bem como o superlativo (relativo) "o melhor" (dia da minha vida), que deixa implícitos os termos comparantes (todos os outros dias até então vividos), mostram que, em situações de crise e de catástrofe, a prioridade tende a ser dada às pessoas, não aos bens materiais.

Em suma, constatamos, ao longo da análise, a construção de uma certa representação - negativa, como não poderia deixar de ser - do episódio ocorrido em Mariana (MG), que mostra, num primeiro momento, pessoas felizes, em harmonia com o meio ambiente, que, quando ocorre o rompimento da barragem, são surpreendidas - daí a presença de índices de avaliação como "estarrecidas" e "desesperada" ou de denominações como "pesadelo", "guerra" - pela enxurrada de lama que invadiu a região. As reações, que vêm em seguida, no póstragédia, dividem os entrevistados em dois grupos: aqueles que, apesar da dor, manifestam ainda fé e esperança de que as coisas voltem ao normal, principalmente com a ajuda de Deus/Jesus (pressupondo-se que apenas a instância divina seria capaz de tal feito) e aqueles que se dizem "tristes" e que mostram desalento diante de uma possível recuperação do meio ambiente, da pureza da água do rio Doce, de onde tiram seu sustento. Eis, em linhas gerais, como se (re)constrói a "dor" indicada no título do caderno. Nessa perspectiva, constatamos que, entre as marcas linguísticas da argumentação, predominam largamente os índices de avaliação e os marcadores de pressuposição sobre outras marcas, como o "não" polêmico e a presença de índices modais e de operadores argumentativos.

\section{Considerações finais}

Charaudeau (2006, p. 146) afirma que as mídias manipulam, com frequência, os leitores/ouvintes, jogando com falsas informações ou notícias exageradamente dramáticas e chegando mesmo à utilização deformada de declarações. Não é nossa pretensão discutir aqui a dimensão do papel das mídias na sociedade atual (isso seria um outro trabalho), mas apenas mostrar que elas se valem das aforizações como um poderoso recurso para atrair a atenção dos destinatários. Afinal, se os profissionais do jornal Estado de Minas destacaram determinados enunciados e não outros, que estariam igualmente disponíveis à aforização, eles construíram, juntamente com os locutores dos depoimentos, representações da tragédia e da forma como ela afetou o meio ambiente e, por extensão, as vidas dos moradores de Mariana (MG) e seus distritos.

Nesse caso, se considerarmos as três provas aristotélicas - éthos, páthos e logos - não é difícil perceber que o Caderno Especial "joga" principalmente com o páthos, buscando sensibilizar/comover o leitor e levá-lo a se solidarizar com as vítimas e a se indignar com o ocorrido. É claro que o teor da matéria - a seriedade da situação ajuda, mas ler relatos daqueles que vivenciaram a tragédia é muito mais eficaz, do ponto de vista argumentativo, do que ler notícias e reportagens produzidas por terceiros. Não à toa o título do caderno é "Vozes de Mariana: a dor em primeira pessoa".

A questão que se coloca para o(a) analista é a de como examinar esses "fragmentos de textos", que são as aforização, de forma o mais objetiva e distanciada possível, sem cair num exercício de pura especulação. Nesse sentido, a proposta da semântica/pragmática de uma argumentação intrínseca à língua pode ajudar-nos a recuperar por meio de "marcas", como o não polêmico, os índices de avaliação, os marcadores de pressuposição, entre outras, a forma como os eventos vão sendo (re)construídos no/pelo discurso, o que justifica, a nosso ver, o diálogo que estabelecemos entre essa vertente dos estudos da argumentação e a ADF. 


\section{Referências}

AMOSSY, Ruth (éd.). Images de soi dans le discours. Paris: Delauchaux \& Niestlé, 1999.

As modalidades argumentativas do discurso. In: LARA, Glaucia M. P. et al. (orgs.). Análises do discurso hoje. Rio de Janeiro: Nova Fronteira, 2008. v. 1, p. 231-254.

La présentation de soi. Ethos et identité verbale. Paris: PUF, 2010.

ANSCOMBRE, Jean-Claude; DUCROT, Oswald. L'argumentation dans la langue. Liège: Mardaga, 1983.

ASSIS, André William Alves de. Sobreasseverações e aforizações: estratégias de sobreasseveração nos debates políticos e de destacamento no discurso jornalístico. 2015. 213f. Tese (Doutorado em Estudos Linguísticos) - Faculdade de Letras, Universidade Federal de Minas Gerais, Belo Horizonte, 2015.

ABREU, Antônio Suárez. A arte de argumentar: gerenciando razão e emoção. Curitiba: Ateliê Editorial, 2003.

CAMPOS, Carla Leila Oliveira; LARA, Glaucia Muniz Proença. $\mathrm{O}$ dito e o silenciado em reportagens sobre tráfico de drogas no Rio de Janeiro: In: EMEDIATO, Wander (org.). A construção da opinião na mídia. Belo Horizonte: NAD/FALE/UFMG, 2013. p. 269-292.

CHARAUDEAU, Patrick. Discurso das mídias. Trad. Ângela M. S. Corrêa. São Paulo: Contexto: 2006.

DUCROT, Oswald. O dizer e o dito. Trad. Eduardo Guimarães. Campinas - SP: Pontes, 1987.

EMEDIATO, Wander (org.). A construção da opinião na mídia. Belo Horizonte: NAD/FALE/UFMG, 2013.

ESTADO DE MINAS. Vozes de Mariana: a dor em primeira pessoa. Caderno Especial. 5 dez. 2012.
$\mathrm{KOCH}$, Ingedore G. V. Argumentação e linguagem. São Paulo: Cortez, 1984.

A inter-ação pela linguagem. São Paulo: Contexto, 1992.

LARA, Glaucia Muniz Proença. Sobreasseveração e aforização nas mídias brasileira e francesa: um estudo comparativo à luz da Análise do Discurso. 2013a. 40f. Relatório de projeto de pesquisa (PósDoutorado em Estudos Linguísticos) Universidade Estadual de Campinas/Université Paris IV - Sorbonne, Campinas/Paris, 2013a.

Passando a aforização em revista. Estudos semióticos, v. 9, n. 2, p. 7-14. São Paulo, USP, 2013b. Disponível em: http://revistas.usp.br/esse/issue/current/showToc.

L'aphorisation dans la presse écrite au Brésil et en France, French Journal for Media Research [en ligne], 2/2014, mis à jour le: 17/07/2014, URL: http://frenchjournalformediaresearch.com/lodel/ind ex.php?id=374.

Pragmatics and Discourse Analysis: a Dialogue on the Concept of Aphorization in Media Texts. Pragmatics, n. 26 (1), march, 2016, p. 93109. Disponível em: http://ipra.ua.ac.be/main.aspx?c=*HOME\&n=1360.

MAINGUENEAU, Dominique. Novas tendências em análise do discurso. Trad. Freda Indursky. Campinas-SP, Pontes, 1993.

Análise do discurso. In: CHARAUDEAU, Patrick; MAINGUENEAU, Dominique (eds.). Dicionário de análise do discurso. Trad. Fabiana Komesu et al. São Paulo: Contexto, 2004. Colin, 2012.

Les phrases sans texte. Paris: Armand Frases sem texto. Trad. Sírio Possenti et al. São Paulo: Parábola, 2014.

VEJA online. Disponível em: http://veja.abril.com.br/complemento/brasil/paraque-nao-se-repita/. Acesso em: 26/05/2016.

\section{COMO CITAR ESSE ARTIGO}

LARA, Glaucia Muniz Proença. A TRAGÉDIA DE MARIANA (MG): AFORIZAÇÕES, MídIAS E ARGUMENTAÇÃO. Signo, Santa Cruz do Sul, v. 42, n. 73, jan. 2017. ISSN 1982-2014. Disponível em: $<$ https://online.unisc.br/seer/index.php/signo/article/view/7853>. Acesso em: http://dx.doi.org/10.17058/signo.v42i73.7853. 